\title{
Divide and rule: A qualitative analysis of the debriefing process in elite team sports
}

\author{
A.-C. Macquet ${ }^{a, *}$, C. Ferrand ${ }^{b}$, N.A. Stanton ${ }^{c}$ \\ ${ }^{a}$ National Institute of Sports, Expertise and Performance (INSEP), Paris, France \\ ${ }^{\mathrm{b}}$ Universite' François Rabelais, Tours, France \\ ${ }^{\mathrm{c}}$ University of Southampton, Southampton, UK
}

a $r$ tic le i $\mathrm{nfo}$

Article history:

Received 16 January 2015

Accepted 14 April 2015

Available online

\section{Keywords:}

Team-work versus task-work expertise

Transformational versus transactional

leadership $\mathrm{a} b \mathrm{~s} \mathrm{t} r \mathrm{a} c \mathrm{t}$

This article aimed to gain an understanding of the process of debriefing during major competitions in elite team sports. Debrief interviews were conducted with 9 head coaches. The interview data were used to identify how head coaches divided up the tasks given to staff and team members prior to, and during the post-match debriefing. Results showed that debriefing consisted of two steps: preparation and presentation. Preparation referred to four successive tasks. Presentation to the team of players consisted of eight tasks relating to transformational and transactional styles of leadership. Coaches were shown to divide the labor within the staff and team. The data tend to support the view that in elite team sports, coaches are both transformational and transactional leaders, adapting their style of leadership to the situation, athletes and time available. This study provides insights into the task-work and team-work underlying team functioning and division of labor.

\section{Introduction}

In sports, debriefing is defined as a discussion between the coach and athlete that is conducted after a competition, with the aim of achieving positive changes and improvements in the following competition (Hogg, 1998). It concerns both performance assessment and athletes' development. Successful debriefing was shown to aid learning, motivation, confidence, psychological and emotional recovery, and self-awareness (Gould et al., 1999; Hogg, 1998, 2002; Milne et al., 1999). It also enables teams to improve performance, decrease negative emotional effects, and foster coacheathlete relationships (Hogg, 2002; McArdle et al., 2010). During successful debriefing, participants reflect on positive and negative components of performance, taking into account technical, tactical, physical and mental aspects (Hogg, 1998). For these reasons, it is essential to debrief athletes after an important competition (Hogg, 1998, 2002; McArdle et al., 2010).

Debriefing appears to be a complex process consisting of many components: (a) self-reflection by the coach and athlete in order to

\footnotetext{
* Corresponding author. Research Department, Laboratory SEP (EA 7370), INSEP, 11 avenue du Tremblay, 75012 Paris, France. Tel.: +33 141744 873; fax: +33 141744 535 .

E-mail address: anne-claire.macquet@insep.fr (A.-C. Macquet)
}

explain what went well and badly; (b) information and vision sharing between the coach and athlete; (c) identification of the need for change regarding technique, strategy, physical and mental preparedness; and (d) goal setting and goal adaptation (Hogg, 2002). Debriefing appears to be a constrained exercise that is conducted by the coach under specific conditions: (a) environment (e.g., quiet place); (b) time (e.g., available time); (c) resources used (e.g., video); and (d) individual or group (McArdle et al., 2010). The coach plays a key role consisting of encouraging the athlete to selfassess as well as giving the athlete feedback to help him/her to progress (e.g., Rees et al., 2012). The coach has to guide the athlete to perceive his/her own potential and limits in order to improve or maintain his/her self-confidence and achieve his/her goals (Hogg, 1998). He/she guides the athlete to provide him/her feedbacks as well as he/she provides athlete feedbacks in order to understand what happened and why. $\mathrm{He} / \mathrm{she}$ also gives athlete instructions about how to achieve positive issues if they encounter such situations again (Hogg, 2002). Even though debriefing is a popular psychological and tactical tool in sports, few attempts have been made to explore the ways coaches prepare for debriefing athletes.

Some have examined the debriefing process from the perspective of coaching (e.g., Macquet, 2009; Omodei et al., 1998). Athletes were shown a video of their performance during a competition. They were encouraged to comment on their focus, perceptions, 

thoughts, and judgments as they made decisions and how they assessed their decision effectiveness. Their comments were then used to highlight self-reflection, including foci and perception (e.g., Omodei et al., 1998), decisions (e.g., Macquet, 2009; Macquet and Fleurance, 2007; Macquet and Kragba, 2015), and performance (Macquet et al., 2012). Such studies showed that video assists the recall of athletes' experiences during competitions, and allowed researchers, coaches and athletes to access some of the thoughts athletes had during their performance, to understand what went well or badly as well as the likely causes. These studies all focused on the debriefing of individuals. They did not report on how to debrief a group in relation to the roles of individuals, their competencies in-game, or their concentration and attention skills during debriefing and so on.

Beyond sport settings, other researchers have debriefed small groups engaged in natural and dynamic environments. Such environments are similar to elite team sports environments as they presents high stakes outcomes, important time pressures and uncertain environments. For example, Mitchells (1983) developed a technique called Critical Incident Stress Debriefing, for use in debriefing small groups of firefighters, paramedics and law enforcement officers. Mitchells calls debriefing following lifethreatening or traumatic situations "psychological first aid". The debriefing interview consists of explaining what happened and what people felt, thought and did during the situation. Such discussions have preventative effects, as debriefed individuals tend to be less depressed, angry and stressed than their non-debriefed colleagues (Bohl, 1991).

These studies of Mitchells (1983) and Bohl (1991) highlighted the psychological benefits of debriefing on individuals. Nevertheless, they did not discuss what individuals should do in the future if they encounter such critical situations again. Moreover, to our knowledge, no studies have focused on debriefing in team sports during major competitions, namely, continental and world championships, and the Olympic Games. Major competitions present intense time pressure, high stakes, and uncertainty. In these competitions, coaches and athletes have only a short time to debrief. Our experience on high level sport and discussions with French team sport coaches tells us that coaches favor a collective debriefing taking place several hours after or the day following the match. They also conduct individual debriefings with some players and semi-collective debriefings involving players with the same role within the team. Furthermore, national coaches work within a group of staff who each have different roles and tasks, including tactical work (i.e., head coaches (HC), assistant coaches (AC), and video coaches (VC), and medics (i.e., doctor and physiotherapist)). As a collective, they undertake a collaborative work: they pursue the same main goals (e.g., Annett and Stanton, 2000), namely debriefing athletes and prepare them for winning major competitions. They can succeed or fail as a whole. To our knowledge, no study has shown how the staff are organized to debrief players, or how a team of players is debriefed. This research focuses on the way the HCs of elite team sports use their experience to debrief a team of players in major competitions.

Research into expert coaches has shown that experts have the ability to identify what novice coaches do not. They provide athletes better feedbacks about possible causes of what happened and better solutions to the problems athletes are facing (e.g., Horton and Deakin, 2008). They also spend much more time providing information about tactics, than technique, and use their time more productively than non experts. Coaches need to be aware of the work-to-rest ratios that enable athletes to recover between practice sessions. They also need to create a climate of trust, consideration, and high expectations when they organize the team-work (e.g., Horton et al., 2005).
Some studies have shown that coaches behave like leaders in organizing their team (e.g., Fletcher and Arnold, 2011). Leadership has been conceptualized as a set of behaviors and leadership styles belonging to an individual (e.g., Bass, 1999; House, 1996; Lewin et al., 1939). Styles may be dictatorial, autocratic, participative or laissez faire (Lewin et al., 1939), directive, supportive, participative or achievement-oriented (House, 1996), and transactional or transformational (e.g., Bass, 1999; Bass et al., 2003). Bass (1999) and Bass et al. (2003) showed that transformational leaders motivate followers to go beyond their self-interest for the greater good, to achieve team goals and emphasize followers' sense of value, self-worth, and confidence by being attentive to followers and expressing followers their own beliefs. Transformational leadership consists of four dimensions: (a) idealized influence $e$ the leader fosters trust and respect among others and serves as mentor to followers; (b) inspired vision e the leader fosters motivation and high expectations, and energizes followers to achieve their goals; (c) intellectual stimulation e the leader incites followers to be creative by questioning and challenging them; and (d) individualized consideration e the leader answers the personal and psychological needs of followers. Transactional leadership is concerned with leader behavior that focused around rewarding appropriate follower behaviors (i.e., contingent reinforcement) and punishment or corrective orientated leader behaviors (i.e., passive and active management by exception; e.g., Arthur et al., 2011). Transactional leaders prefer avoiding risk, focus on time constraints and efficiency and try to maintain control on followers. This theory of leadership style is well-suited to study the leadership styles sport coaches adopt while debriefing their athletes.

Research in leadership indicates that the leader organizes the way the work must be done by the team. He/she organizes the team-work. Research in leadership in sport setting has focused on: (a) leadership styles (e.g., Fletcher and Arnold, 2011; Rowold, 2006; Vidic and Burton, 2011); (b) the effects of transformational leadership style on intrinsic motivation (Charbonneau et al., 2001) and well-being (Stenling and Tafvelin, 2014); and (c) the role of athlete narcissism in moderating the relationship between coaches' transformational leadership and athlete motivation (Arthur et al., 2011). It has not studied how the HCs debrief a team of athletes in elite team sports. The current study aimed to gain a better understanding of the process of debriefing in elite team sports, during major competitions including intense time pressure and high stakes. More specifically, it aimed to explain what tasks are carried out to debrief athletes during major competitions as well as the division of labor between staff.

\section{Method}

\subsection{Participants}

Nine HCs volunteered to participate in this study (seven men and two women). The criteria used to select them included being $\mathrm{HC}$ of national senior sport teams' of male or female players and having participated in major competitions. Four of the teams had previously won medals in continental and world championships and/or the Olympic Games. Coaches work with their national team for specific and short periods during the year in order to prepare for the major competitions. HCs were given pseudonyms to provide some degree of confidentiality (HC1 to HC9). Participants included HCs of volleyball, basketball, handball, and field and ice hockey teams. They ranged in age from 34 to 60 years $(M=46.5$ years, $S D=8$ years) and each had more than two years of experience with national teams, except $\mathrm{HC} 6$ and $\mathrm{HC} 7$, who were novice national $\mathrm{HCs}$ but had participated in the qualifying major competitions for the 
London Olympic Games. The study was approved by a local ethics committee.

\subsection{Data collection}

In order to collect rich data to portray complex human experiences (Per $\epsilon_{a k y l} \notin$ and Ruusuviori, 2011), a qualitative design was adopted in this study. This design is well-suited to exploring the

process used by individual working in natural settings such as coaches debriefing athletes in elite team sports during major competitions. It focuses on the early stages of the scientific method. It enables to understand phenomena such as the debriefing process in elite team sports. It also allows in-depth understanding of the phenomenon of interest, particularly when access to participants is limited (Klein, 2013).

To understand how HCs debriefed a team under intense time pressure and high stakes, HCs were interviewed about their practice in continental and world major competitions. Such major competitions take place over a 2 -week period, with a match every one or two days. Semi-structured interviews were conducted with each HC separately. They were conducted during three weeks and five months following such major competitions, depending on HCs' availability. Interviews conducted several months after the major competitions were with the most experienced HCs in major competitions. HCs were asked to explain how, when and with whom they prepared their debriefings and debriefed athletes. The interviewer used specific prompts to encourage the participant to described the way he/she prepared and presented debriefing to players (e.g., What kind of information did you take into account to prepare for your debriefing? What did you expect from players?).

Interviews were conducted by one person (the lead author), who had already conducted such interviews in previous studies. The full interviews were recorded and then transcribed. They lasted between $1 \mathrm{~h} 30 \mathrm{~min}$ and $2 \mathrm{~h} 39 \mathrm{~min}(M=1 \mathrm{~h} 58 \mathrm{~min} ; S D=25 \mathrm{~min})$.

\subsection{Data processing}

Data processing comprised four steps. The first one was done using a comparative method (Corbin and Strauss, 1990). This method aims to identify participants' main concern and how they manage it. The core questions the researcher continuously asks are: "What's going on?" and "What are they doing when they prepare the debriefing?" The method consists of generating concepts that explain the way individuals cope with the tasks to be carried out, regardless of time and place. Concepts are generated from inductive and deductive analysis. In the present study, the method aimed to model the debriefing process used by $\mathrm{HCs}$ of elite team sports during major competitions. Interview transcripts were divided into meaningful units regarding the tasks done or organized by the HCs (i.e., concerns). The properties of these meaningful units were compared and classified into first order categories according to their common features. Each category was labeled and their properties defined. As the data analysis proceeded, two other levels of interpretation emerged from a comparison between properties of categories (i.e., core concepts, see Table 1 and Fig. 1). Two researchers analyzed the verbal reports separately. The data were constantly compared until saturation was reached, which occurred when no more new categories emerged from the data. Saturation was reached during the processing of the eighth interview. After each step, the researchers compared their results and discussed any initial disagreement until consensus was reached. The reliability of the coding procedure was assessed with Bellack's agreement rate (Von Someren et al., 1994). The initial agreement rate for the identification and categorization of the meaningful units was $92 \%$ which exceeds the desired reliability threshold. A total of 441 meaningful units were identified and classified into 14 first order categories.

In the second step, researchers assessed the frequencies of each category reported by $\mathrm{HCs}$ and compared them. They also assessed the ratio concerned with the frequencies of tasks reported by HCs in relation to each of the two highest levels of interpretation (i.e., see Table 2).

In the third step, the task identified was compared within the categories for transformational and transactional leadership styles (Bass, 1999; Bass et al., 2003). Each task was categorized within either the dimensions of the transactional leadership style, namely rewarding followers behaviors and punishment or corrective orientated leader behaviors, or within the four dimensions of the transformational leadership style, namely, (a) idealized influence; (b) inspiring vision; (c) intellectual stimulation; and (e) individualized consideration.

In the fourth step, they total the frequency of each kind of task related to transformational or transactional leadership styles was summed for each $\mathrm{HC}$ and the corresponding ratio to demonstrate micro-styles of leadership among HCs calculated.

\section{Results}

The core concepts to emerge from the analysis pertaining to debriefing were preparation and presentation. Each concept

Table 1

Examples of meaningful units, first, second and third order categories.

\begin{tabular}{|c|c|c|c|}
\hline $\begin{array}{l}\text { Third order } \\
\text { categories }\end{array}$ & $\begin{array}{l}\text { Second order } \\
\text { categories }\end{array}$ & First order categories & Meaningful units \\
\hline \multirow{6}{*}{$\begin{array}{l}\text { Debriefing } \\
\quad \text { preparation }\end{array}$} & \multicolumn{2}{|c|}{ Preparation of video material } & "The VC records the match and sequences it by game areas. \\
\hline & \multirow[t]{3}{*}{$\begin{array}{l}\text { Assessment of own } \\
\text { team's game }\end{array}$} & Efficiency of game plan and plan implementation & "I analyze whether they respect the game plan". HC 4 \\
\hline & & $\begin{array}{l}\text { Possible causes of players' good and poor } \\
\text { performance in different game areas }\end{array}$ & $\begin{array}{l}\text { "We should have succeeded in this play. I watch players to } \\
\text { see their timing and coordination with partners to } \\
\text { understand what went wrong". HC } 2\end{array}$ \\
\hline & & Areas of improvement for the following match & $\begin{array}{l}\text { "We lost many balls at the center of the pitch. We must } \\
\text { tell players to pay more attention to this area". HC } 8\end{array}$ \\
\hline & \multicolumn{2}{|c|}{ Discussion with the staff and lead players about the game assessment } & $\begin{array}{l}\text { "I need information from all my staff because players don't } \\
\text { tell me important things that they tell the assistant or } \\
\text { physiotherapist". HC } 4\end{array}$ \\
\hline & \multicolumn{2}{|c|}{ Development of material to present the game assessment to players } & $\begin{array}{l}\text { "I choose three or four meaningful game sequences. } \\
\text { I choose an offensive game sequence and two defensive } \\
\text { sequences". HC } 7\end{array}$ \\
\hline $\begin{array}{l}\text { Debriefing } \\
\text { presentation }\end{array}$ & $\begin{array}{l}\text { Transactional } \\
\text { leadership style }\end{array}$ & Acknowledgment of players' work and reward & $\begin{array}{l}\text { "We congratulate a player who worked well, or faced } \\
\text { difficulties in order to encourage her". HC } 9\end{array}$ \\
\hline
\end{tabular}




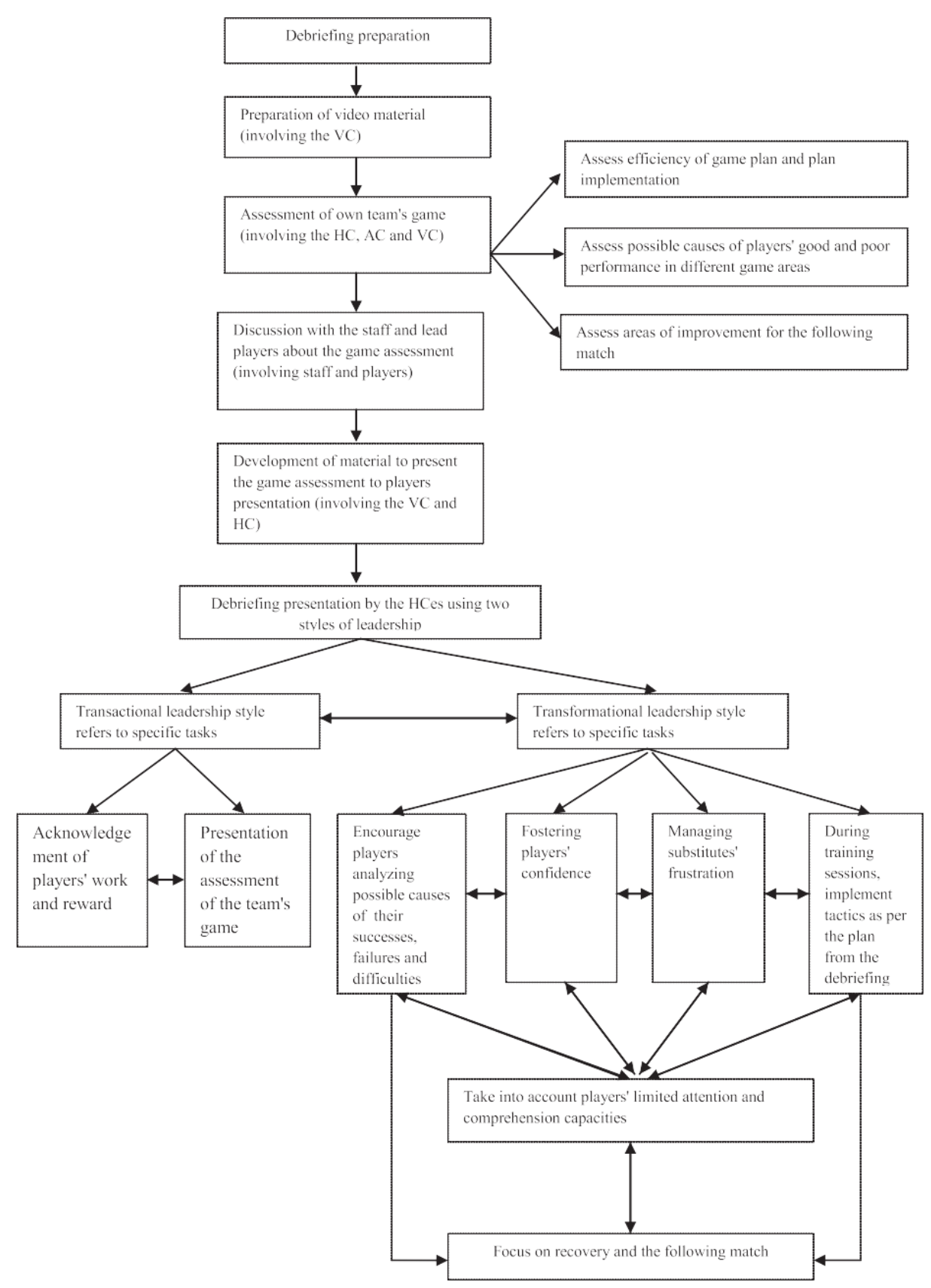

Fig. 1. Model of the debriefing process in elite team sports.

contained a set of sub-tasks: four for the debriefing preparation and eight for the debriefing presentation. An overall model of the debriefing process is presented in Fig. 1.

\subsection{Debriefing preparation}

Before debriefing a team of players, all HCs prepared exactly what they wanted to say and show team. Preparing the debriefing enabled coaches to save time for the players' physical and mental recovery. Coaches tried to provide players information solely about critical situations and what individuals should do in the future if they encounter the same situations. The main part of the preparation consisted of analyzing the efficiency of players' actions, behaviors and attitudes during the game, using a video of the match. It aimed to assess the team's game and highlight some important information to team relating to contrast between what players did and should do. Results showed debriefings were collaborative work. In each case, all the staff were involved in preparing debriefings, including $\mathrm{HC}, \mathrm{AC}, \mathrm{VC}$, doctor and physiotherapist. All HCs managed the debriefing, giving each member specific tasks and roles. Four main tasks were elicited: (a) preparation of video material; (b) assessment of own team's game; (c) discussion with staff and lead players about the game assessment; and (d) development of material to present the game assessment to players. Each task was undertaken by specific persons nominated by the $\mathrm{HC}$.

Firstly, HCs reported that the VC prepared the video material. $\mathrm{He} / \mathrm{she}$ recorded a video of the game or obtained one from the major competitions organizer or opponents' team VC, and then sequenced it according to the game areas (e.g., turnovers). VCs used specific software to sequence the video and produce statistics on 
Table 2

Frequencies of tasks according to $\mathrm{HCs}$, and their ratio.

\begin{tabular}{|c|c|c|c|c|c|c|c|c|c|c|c|c|}
\hline Second order categories & First order categories & $\mathrm{C} 1$ & $\mathrm{C} 2$ & $\mathrm{C} 3$ & $\mathrm{C} 4$ & C5 & $\mathrm{C} 6$ & $\mathrm{C} 7$ & $\mathrm{C} 8$ & C9 & $\mathrm{n}$ & $\mathrm{R}$ \\
\hline \multicolumn{13}{|c|}{ Third order categories: debriefing preparation } \\
\hline Preparation of video material & & 2 & 3 & 3 & 5 & 3 & 6 & 3 & 4 & 2 & 31 & .14 \\
\hline \multirow[t]{3}{*}{ Assessment of own team's game } & Efficiency of game plan and plan implementation & 8 & 9 & 2 & 3 & 1 & 8 & 5 & 3 & 1 & 50 & .22 \\
\hline & Possible causes of players 'good and poor performance in different game areas & 5 & 7 & 4 & 4 & 2 & 10 & 11 & 6 & 4 & 53 & .23 \\
\hline & Areas of improvement for the following match & 2 & 1 & 3 & 1 & 1 & 8 & 10 & 3 & 1 & 30 & .12 \\
\hline \multicolumn{2}{|c|}{ Discussion with the staff and lead players about the game assessment } & 2 & 3 & 3 & 5 & 2 & 4 & 3 & 7 & 2 & 31 & .13 \\
\hline \multicolumn{2}{|c|}{ Development of material to present the game assessment to players } & 4 & 5 & 3 & 1 & 2 & 8 & 5 & 6 & 2 & 36 & .16 \\
\hline \multicolumn{13}{|c|}{ Third order categories: debriefing presentation } \\
\hline \multirow[t]{2}{*}{ Transactional leadership style } & Acknowledgment of players' work and reward & 5 & 5 & 1 & 7 & 7 & 7 & 13 & 5 & 3 & 53 & .25 \\
\hline & Presentation of the assessment of the team's game & 9 & 7 & 4 & 4 & 3 & 20 & 35 & 5 & 4 & 91 & .44 \\
\hline \multirow[t]{6}{*}{ Transformational leadership style } & Leading players of analysis possible causes of successes, failures and difficulties & 2 & 1 & 1 & 1 & 0 & 3 & 1 & 1 & 1 & 11 & .05 \\
\hline & Fostering players confidence & 0 & 2 & 0 & 2 & 0 & 1 & 0 & 1 & 2 & 8 & .04 \\
\hline & Managing substitutes' frustration & 2 & 1 & 0 & 0 & 0 & 0 & 0 & 0 & 0 & 3 & .02 \\
\hline & During a training session, implement tactics as per the plan from the debriefing & 2 & 0 & 1 & 0 & 0 & 0 & 0 & 1 & 3 & 7 & .03 \\
\hline & Take into account players' limited attention and comprehension capacities & 1 & 1 & 1 & 1 & 2 & 2 & 1 & 1 & 1 & 11 & .05 \\
\hline & Focus on recovery and the following match & 3 & 2 & 1 & 4 & 8 & 3 & 2 & 2 & 1 & 26 & .12 \\
\hline
\end{tabular}

Note: $\mathrm{C} 1$ to $\mathrm{C} 9=\mathrm{HC} 1$ to $\mathrm{HC} 9, \mathrm{HC} 7$ and $\mathrm{HC} 9$ were female $\mathrm{HCs}, \mathrm{n}=$ frequency of first order category, $\mathrm{R}=$ ratio.

achieved and failed individual and collective actions. For example, HC 2 said: "The VC records the match and sequences it by game areas so I can analyze the entire match or sequenced match."

Secondly, the results indicated that HCs and ACs assessed their own team's game using the video of the game. Their analysis was structured according to (a) efficiency of the game plan and plan implementation; (b) possible causes of players' strong and poor performance in different game areas; and (c) areas of improvement for the following match. Before playing a match, coaches drew up a game plan to implement in relation to own team and opponents' team strengths, weaknesses, and tendencies. This plan reflected what players were required to do to achieve positive outcomes in the different game areas. It was prepared from anticipation of the opponents' game based on the play during current and previous major competitions. If this anticipation was proved wrong, the plan might fail and the team would need to change it during the course of the game. If it was correct, it might achieve positive outcomes. Results showed that in debriefing preparation, HCs assessed the appropriateness of the plan according to the opponent team's plan and performance in the match, the quality of own team plan implementation and the difficulties in implementation. For example, HC 4 said: "I analyze whether they respect the game plan." Results showed that HCs reflected on players' strengths and weaknesses based on what went well and badly and looked for possible causes. For example, HC 4 said:

"I ask my VC to statistically assess the balance of power between the serve and reception, the hit and defense and the block and defense. It allows [us] to know where we did well and badly. Is it because of poor serves?"

Once the analysis was completed, HCs reflected on areas for improvement in the following match. For example, HC 8 said: "We lost a lot of balls in the center of the pitch. We must tell players that they should pay more attention in this area."

Thirdly, HCs discussed the game with ACs, VCs and lead players to ensure they agreed with the analysis. They also discussed the players' mental and physical fitness with the medical staff. For example, HC 7 said: "The physiotherapist sees and massages the players. He starts with the injured ones. He then tells me about the players: this one feels tired."

Fourthly, HCs asked VCs to develop material to present the game assessment to the players. They requested that VCs compile footage of what players did well and badly (see Fig. 1). For example, HC 1 said: "I want him to select all plays four [meaning a kind of pattern of coordination among players]. I want this one, which is good, and also that one, which is unsatisfactory."

Results demonstrated that the task most frequently requested by HCs was assessment of their own team's game (see Table 2).

\subsection{Debriefing presentation}

All HCs said that they minimized the length of the debriefing presentation in order to allow players the maximum time for recovery. They debriefed players in a quiet room at the hotel, with chairs oriented towards a screen and a flip chart, like a classroom. Presentations lasted between 10 and 45 min, depending on available time before the following match.

\subsubsection{Tasks and leadership styles}

Eight tasks were generated from the results data. As data was being analyzed, these tasks were then related to two transactional and transformational styles (Bass, 1999). The tasks related to transactional leadership style were: (a) acknowledgment of players' work and reward $e$ in relation to the dimension on contingent rewards, and (b) presentation of the assessment of the team's game e in relation to the dimension on corrective orientated leader behaviors. The tasks related to transformational leadership style were: (a) leading player analysis of possible causes of successes, failures and difficulties $e$ in relation to the dimension on intellectual stimulation; (b) fostering players' confidence $e$ in relation to the dimension on inspiring vision; (c) managing substitute frustration; (d) taking into account players' limited attention and comprehension capacities; and (e) during a training session, implementation of tactics as per the plan from the debriefing $e$ these last three tasks are in relation to the dimension on individualized consideration; and (f) focus on recovery and the following match $e$ in relation to the dimension on inspiring vision.

Results indicated that all HCs used a transactional leadership style. HCs started debriefing teams by acknowledging which players did well and which performed poorly; some HCs rewarded players. For example, HC 9 said: "We congratulate a player who worked well or faced difficulties, in order to encourage her." They presented the assessment of the team's game. For example, HC 3 said: "I give them my game analysis. I set performance in relation to statistics and actions that went badly" (see Fig. 2).

$\mathrm{HCs}$ were shown to use a transformational leadership style. They encouraged players to analyze possible causes of their 


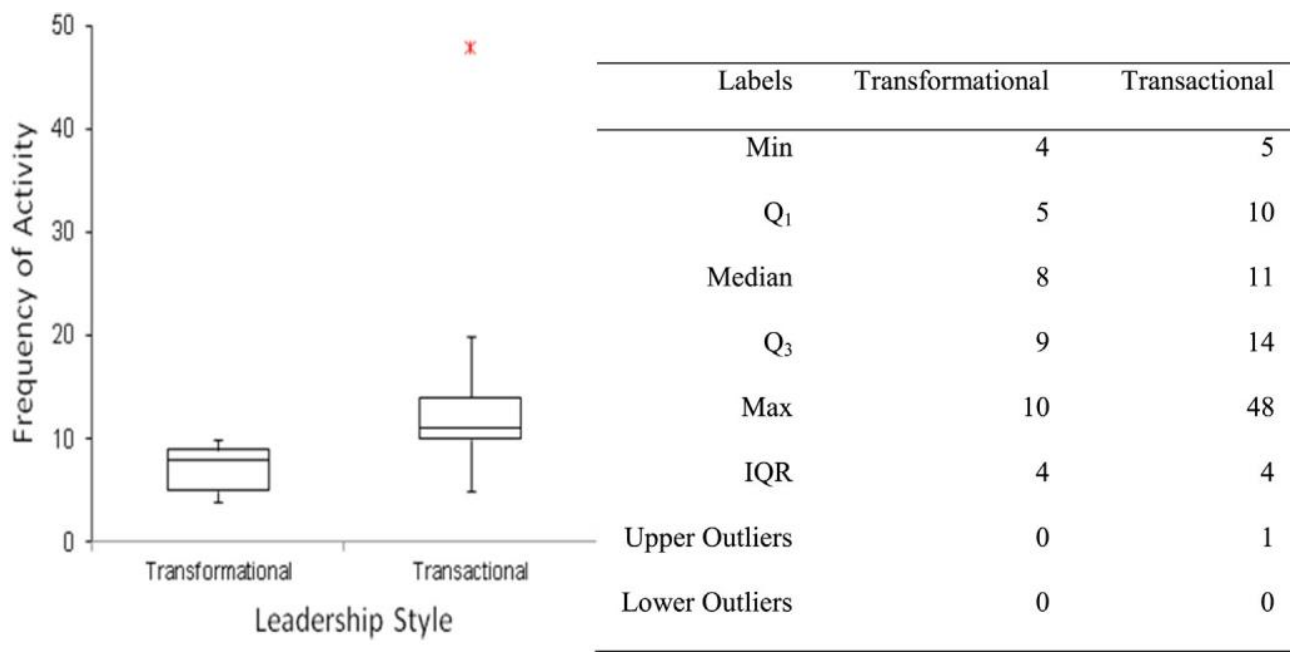

Fig. 2. Box and Whisker plot of the frequencies of activities in transformational and transactional leadership.

successes, failures and difficulties. For example, HC 6 said: "We ask them questions to help them understand why this happened." They fostered players' confidence when players had difficulties and lost the match. For example, HC 8 said: "You did your best. You lost because they're much better than you. You have to persevere." Players selected for a national team were the best, or one of the best players in their club. Each team contains main players and substitutes whom role is to replace main players temporarily when main players are tired, injured and so on. Consequently, substitutes wanted to be a main player instead of being a substitute. According to the needs of the team at each moment, HCs selected some players to play instead of others. At the end of a match, HCs had to manage substitutes' frustration and make them understand that the team needed them because they were resources for the team. For example, HC 1 said: "I tried to stress each player's role. Substitute players are often responsible for the team's level of play; we need them. I tell them what I expect them to do." Results also showed that HCs took into account players' limited attention and understanding capacities due to the fatigue of players during major competitions and differences between players. For example, HC 5 said: "If you show them a video, drawings and analysis they don't understand, it is useless." During a training session, players implemented tactics according to the plan from the debriefing. For example, HC 9 said: "We debrief before the training session to allow them to put what we said into practice". Finally, results demonstrated that HCs wanted players to move on from the game and focus on recovery and the following match. For example, HC 6 said: "After this match, we debriefed for $10 \mathrm{~min}$ : we congratulated the players and focused on the following match."

The results did not elicit any tasks in relation to the dimension on idealized influence within the transformational leadership style.

\subsubsection{Tasks, leadership styles and ratios}

The data led to the identification of two kinds of ratio. They were related to the frequencies of tasks reported by $\mathrm{HCs}$ in relation to debriefing preparation (i.e., first kind) and debriefing presentation (i.e., second kind). The tasks most frequently reported by HCs were presenting the assessment of the team's game, and acknowledgment of players' work and reward. By adding the frequency of each kind of task related to transformational or transactional leadership styles for each $\mathrm{HC}$ and calculating the corresponding ratio, results showed four micro-styles of leadership among HCs (see Table 3). Because each coach was partly a transactional and transformational leader, these micro-styles enabled to characterize more precisely the style of leadership of each coach. These micro-styles have been called 'evens transformational' (where the ratio of transformational and transactional activities was approximately the same), 'thirds transformational' (where transformational activities were approximately one-third of total activities), 'quarters transformational' (where transformational activities were approximately one-quarter of total activities) and 'twelfths transformational' (where transformational activities were approximately one-twelfth of total activities). HCs 6 and 7 were the more junior of the cohort. Three of the five HCs demonstrating the leadership micro-style 'evens transformational' won medals in major competitions. The four HCs who won medals with their team displayed the 'thirds trans' formational' micro-style. This suggest that the 'evens' and 'third' leadership styles are generally associated with more successful coaches than the other ratios, which is a point worthy of note from the study.

\section{Discussion}

The results are discussed in relation to two sets of findings concerned with collaborative work, coaching and leadership. The first concerns the assessment of tactical work undertaken by

Table 3

Frequencies and ratio of activities for transformational and transactional leadership styles.

\begin{tabular}{lccrl}
\hline Coach & Transformational & Transactional & $\mathrm{n}$ & Leadership style (by ratio) \\
\hline $\mathrm{C} 1$ & $10(.42)$ & $14(.58)$ & 24 & Evens \\
$\mathrm{C} 2$ & $7(.37)$ & $12(.63)$ & 19 & Thirds \\
$\mathrm{C} 3$ & $4(.44)$ & $5(.56)$ & 9 & Evens \\
$\mathrm{C} 4$ & $8(.42)$ & $11(.58)$ & 19 & Evens \\
$\mathrm{C} 5$ & $10(.50)$ & $10(.50)$ & 20 & Evens \\
$\mathrm{C} 6$ & $9(.24)$ & $27(.76)$ & 38 & Quarters \\
$\mathrm{C} 7$ & $4(.08)$ & $48(.92)$ & 52 & Twelfths \\
$\mathrm{C} 8$ & $5(.33)$ & $10(.67)$ & 15 & Thirds \\
$\mathrm{C} 9$ & $8(.53)$ & $7(.47)$ & 15 & Evens \\
$\mathrm{n}$ & $62(.30)$ & $147(.70)$ & 209 & \\
Median & 8 & 11 & & \\
\hline
\end{tabular}

Note: numbers in brackets are the ratio, Evens = approximately the same ratio between transformational and transactional, Thirds $=$ transformational activities were approximately one-third of total activities, Quarters = transformational activities were approximately one-quarter of total activities, Twelfths $=$ transformational activities were approximately one-twelfth of total activities. 
players during a game, and its implications for the work to be done in the following match, namely, the task-work. The second concerns the work carried out by the staff to enable players to do their work, namely, the team-work.

\subsection{Assessment of tactical work done by players during a game and its implications}

Results showed that the staff's main task in preparation for the debriefing was assessment of their own team's game during the previous match and discussion of it with the players. The findings also showed that assessment of their own team's game related to the appropriateness of the game plan and the efficiency of its implementation, as well as the analysis of possible causes of good and poor performance. These assessments were supplemented by the areas for improvement in the following match, namely, what needed to be undertaken in order to maintain or improve performance and what could be expected from players in the following match. This suggests that debriefing is a process that is oriented towards both the past and the future. Debriefing appears to be a reflective and constructive process that is anchored in athletes' learning and development, consistent with Hogg's (1998, 2002), and McArdle et al.'s (2010) results. This also suggests that in team sports, debriefing starts with the game assessment made by the staff and lead players (i.e., debriefing preparation) and then continues with a discussion with all players, led by the HC (debriefing presentation). Preparation for the debrief resulted in time being saved for the discussion with players. It also meant the discussion could focus on three or four main problems that occurred during the game. These results are inconsistent with previous results on debriefing, which suggested that discussions involved only a coach and athlete (Hogg, 1998, 2002; McArdle et al., 2010). To our knowledge, no study has reported on these two steps of the debriefing process. Exploring debriefing in other teams and countries could be a worthwhile avenue for future research.

Individual assessment of the own team's game was then supplemented by discussions within the tactical staff, between tactical staff and lead players, and between the $\mathrm{HC}$ and medical staff about players' mental and physical fitness. Results showed that HCs tried to build a comprehensive picture of the game played and players' performances. HCs could not build such a picture, alone; they needed input from the video sequences of the match and others' opinion on each player's role within the team. Results suggest that debriefing was a collaborative process involving lead players, tactical and medical staff. To our knowledge no study has yet shown such collaboration between staff and lead players in team debriefing. Results also suggest that individuals within the team had different interpretations of the game played. These results are consistent with Macquet's (2013) and Macquet and Stanton's (2014) studies on distributed cognition between the coach and athlete, and Stanton et al.'s (2006) and Stanton et al.'s (2010) studies on distributed situation awareness in military teams. These last studies showed that individuals had different interpretations of the situation depending on their role within the team, their competencies and their experience (Stanton et al., 2015).

Finally, the results indicated that the work was divided within the team of players and staff, according to individuals' roles. Each individual gave specific information to the tactical staff. The HC then decided what to highlight to the athletes. In line with Fletcher and Arnold's (2011) results and Annett and Stanton (2000), HCs involved each individual within the staff and encouraged their contribution to a collaborative vision of the team and improved team performance. No study to date has reported on division of labor in debriefing athletes. It would be of interest and use in future research to encourage exploring debriefing in other sports and contexts.

\subsection{Enhancing the work carried out by the staff to enable players to do their work}

The results showed that in order to debrief a team, HCs organized tasks into two leadership styles: transactional and transformational. Analysis of these results demonstrated that HCs used transactional leadership when presenting their assessment of the team's game to players. This presentation is consistent with the characteristics of transactional leadership (Bass, 1999). Transactional leaders provide players with pragmatic paths to goals. They give them solutions to the problems raised instead of encouraging players to find solutions on their own. Nevertheless, they are open to their players' suggestions.

It was seen that HCs acknowledged the work of players and rewarded them. These results add weight to the suggestion that $\mathrm{HCs}$ are transactional leaders, who give players contingent rewards.

In the transformational leadership style, $\mathrm{HCs}$ encouraged players to analyze possible causes of achievements, failures and difficulties. Leading the players in analyzing video sequences suggests that HCs wanted athletes to undertake their own independent analysis of the game. They wanted athletes to think for themselves and contribute to the decision-making process. They helped athletes to be more confident when they faced problems and strengthened their ability to solve them. This intellectual stimulation is consistent with that described by Bass (1999) to explain his model of transformational leadership.

Results indicated that HCs tried to foster players' confidence. To improve confidence, they explained the areas for improvement in the following match. In this way, they instilled a sense of optimism in athletes and led athletes to do more than they first thought possible. These results are consistent with the dimension concerned with inspiring vision within transformational model of leadership (Bass, 1999). Transformational leaders are expected to inspire confidence and optimism in the group in order to achieve high positive outcomes in the near future. The confidence was not assessed in the following match.

The HCs also managed substitutes' frustration when substitutes had not played in the match for as long as they would have liked to. $\mathrm{HCs}$ spent time developing a vision of the team in which each member went beyond immediate self-interest and contributed to the team's success according to his/her role; they inspired players to make an extra-effort, and to exhibit persistence and determination, consistent with the dimension concerned with inspiring vision within transformational model of leadership (Bass, 1999; Callow et al., 2009; Fletcher and Arnold, 2011).

The HCs took into account players' limited attention and understanding capacities in a context of numerous disruptions and fatigue. Results suggest that $\mathrm{HCs}$ displayed genuine care and concern for players' needs and abilities during the game and the debriefing presentation. These results are consistent with bounded rationality as explained by Simon (1996), individualized consideration as described by Bass (1999) within transformational leadership, and a climate of consideration done by expert coaches as by reported Horton et al. (2005). The results also suggest that HCs were close to players; HCs paid attention to players and took care of them, consistent with Jowett and Clark-Carter's (2006) 3 p 1Cs model of coacheathlete relationships.

Results also showed that some HCs implemented tactics during a training session in accordance with the plan from the debriefing. The training session was used to complement the debriefing session. It allowed the HCs to actively demonstrate what was said to players and to promote players' empowerment and team spirit, 
consistent with the individualized dimension within transformational leadership model (Bass, 1999).

Finally, results showed that at the end of the debriefing presentation HCs focused on recovery and the following match. HCs wanted players to stop focusing on past performance and switch to focusing on an attractive vision of the future. Changing focus and articulating an inspiring vision to the players fostered inspirational motivation, consistent with the transformational leadership model (Bass, 1999).

Results did not show any tasks concerned with the dimension of idealized influence within the transformational leadership style. This suggests that this dimension must be considered by the players who decide if the leader serves as a charismatic role to followers (e.g., Judge et al., 2006). Articulating the interviews with the staff and players could be of interest for future research. It will enable to get a larger picture of the debriefing process in team and individual sports, and other contexts.

The results suggest that $\mathrm{HCs}$ were both transactional and transformational leaders. According to Bass (1999), the best leaders are both transactional and transformational, depending on the situation, athletes and available time; unfortunately, the results did not indicate whether female HCs were more transformational than transactional, as proposed by Bass (1999), as only two participants were female. Exploring the differences between male and female HCs could open other possibilities for future research in sports and other contexts.

In the results, it appeared that HCs 6 and 7, who were the more junior of the cohort, had lower transformational than transactional ratios. According to Bass's (1999) model, it would be expected that their style would move to the 'thirds transformational' or 'evens transformational' over time, like those of more experienced HCs and those of $\mathrm{HCs}$ whose teams won medals in major competitions, that is to say, a reduction would be expected in the proportion of transactional leadership activities with a corresponding increase in the proportion of transformational leadership activities as these HCs become more experienced.

At the applied level, and to go beyond Hogg's (1998, 2002) work in individual sports, it is important to develop the research into task-work, including use of different resources to assess a team's game (e.g., efficiency of the game plan and plan implementation), understanding what happened and why (e.g., possible causes of players' good and poor performance in different game areas), and determining the team's needs for the following match (e.g., pay attention to a specific area of the pitch). It is also important to develop the research into team-work, including division of labor (i.e., who does what and when?), and transformational and transactional leadership styles as a strategy for improving the performance of athletes and helping them achieve their fullest potential. Ways to develop leadership are a fruitful area for future leadership research (Bass et al., 2003). Leadership might be developed by focusing on tasks to be done (e.g., a specific pattern of coordination among players), rather than on expected behaviors (e.g., successful behaviors). Changing the tasks might also lead individuals to change the way they automatically carry out tasks. For example,

This study has some limitations. Firstly, it did not compare the findings with other HCs. The way debriefing is conducted by staff and lead players for different matches and countries is not known yet. There are very few studies on debriefing in elite team sports, and sport psychology research has often involved few participants because only a small number of HCs manage elite teams (Macquet, 2010). Secondly, the study focused on debriefing using interviews with only the HCs. Although the $\mathrm{HCs}$ have a prominent role in debriefing, exploring the ways in which staff and players debrief team games could provide additional information. Thirdly, the study centered on the match debriefing. Whereas this debriefing is important, it would be of interest studying the debriefing the staff did about the debriefing the HCs present to the players, and the effects of debriefing on the following matches and team success within the major competitions.

\section{Conclusion}

The data collected in this study enabled us to model the debriefing process used by $\mathrm{HCs}$ in elite team sports during major competitions involving intense time pressure and high stakes. In addition to the presentation to players and discussion between HCs and athletes, debriefing in team sports required a preparation step largely driven by the HCs. Results highlighted the collaborative work undertaken by the staff and team. They indicated the tasks carried out by the staff and team while debriefing players and how the HCs determined the work to be performed by the players in the following match. The data tend to support the view that, in elite team sports, HCs are both transformational and transactional leaders, adapting their style of leadership to suit the situation, athletes and available time. This study provides insights into the task-work and team-work underlying team functioning, coaching and leadership within elite sports and the division of labor. Further research is needed on debriefing to improve our understanding of team functioning, coaching and leadership within elite sports and other contexts.

\section{Acknowledgments}

This study was supported by a grant from the French Ministry of the City, Youth and Sports ( $\left.\mathrm{n}^{0} 11-\mathrm{I}-39\right)$. The authors are grateful to the coaches for their participation in this study.

\section{References}

Annett, J., Stanton, N.A., 2000. Editorial Team-work e a problem for ergonomics? Ergonomics 43 (8), 1045e1051.

Arthur, C.A., Woodman, T., Weig On, C., Hardy, L., Ntoumanis, N., 2011. The role of athlete narcissism in moderating the relationships between coaches' transformational leader behaviors and athlete motivation. J. Sport Exerc. Psychol. 33, $3 \mathrm{e} 19$.

Bass, B.M., 1999. Two decades of research and development in transformational leadership. Eur. J. Work Organ. Psychol. 8 (1), 9e32.

Bass, B.M., Avolio, B.J., Jung, D.I., Berson, Y., 2003. Predicting unit performance by assessing transformational and transactional leadership. J. Appl. Psychol. 88, 207e218. http://dx.doi.org/10.1037/002169010.88.2.207.

Bohl, N., 1991. The effectiveness of brief psychological interventions in police officers after critical incidents. In: Reese, J.T., Horn, J., Dunning, C. (Eds.), Critical Incident in Policing. Department of Justice, Washington, DC, pp. 31e38.

Callow, N., Smith, M.J., Hardy, L., Arthur, C.A., Hardy, J., 2009. Measurement of transformational leadership and its relationships with team cohesion and performance level. J. Appl. Sport Psychol. 21, 395e412. http://dx.doi.org/ 10.1080/10413200903204754.

Charbonneau, D., Barling, J., Kelloway, E.K., 2001. Transformational leadership and sport performance: the mediating role of intrinsic motivation. J. Appl. Soc. Psychol. 31 (7), 1524e1534.

Corbin, J., Strauss, A., 1990. Basics of Qualitative Research: Grounded Theory. Procedures and Techniques. Sage, Newbury Park, CA.

Fletcher, D., Arnold, R., 2011. A qualitative study of performance leadership and management in elite sport. J. Appl. Sport Psychol. 23, 223e242. http:// dx.doi.org/10.1080/10413200.2011.559184.

Gould, D., Guinan, D., Greenleaf, C., Medbery, R., Peterson, K., 1999. Factors affecting Olympic performance: perceptions of athletes and HCs from more and less successful teams. Sport Psychol. 13, 371e395.

Hogg, J.M., 1998. The post performance debriefing process: getting your capable track and field athletes to the next level of performance. IAAF Q. 3, 49 e57.

Hogg, J.M., 2002. Debriefing: a means to increasing recovery and subsequent performance. In: Kellemann (Ed.), Enhancing Recovery: Preventing Underperformance in Athletes. Human Kinetics, Champaign, IL, pp. 181e198.

Horton, S., Deakin, J.M., 2008. Expert coaches in action. In: Farrow, D., Baker, J., MacMahon, C. (Eds.), Developing Sport Expertise. Taylor and Francis, London \& New York, pp. 75 e88.

Horton, S., Baker, J., Deakin, J.M., 2005. Experts in action: a systematic observation of 5 national team coaches. Int. J. Sport Psychol. 36, 299e319. 
House, R.J., 1996. Pathegoal theory of leadership: lessons, legacy, and a reformulated theory. Leadersh. Q. 7 (3), 323e352.

Jowett, S., Clark-Carter, D., 2006. Perceptions of empathic accuracy and assumed similarity in the HCeathlete relationship. Br. J. Soc. Psychol. 45, 617e637. http:// dx.doi.org/10.1348/014466605X58609.

Judge, T.A., Fluegge Wolf, E., Hurst, C., Livingston, B., 2006. Charismatic and transformational leadership. Organ. Psychol. 50 (4), 203e214. http://dx.doi.org/ 10.1026/0932-4089.50.4.203

Klein, G., 2013. Seeing What Others Don't. The Remarkable Ways We Gain Insights. Public Affairs, New York, NY.

Lewin, K., Lippitt, R., White, R.K., 1939. Patterns of aggressive behaviour in experimentally created social climates. J. Soc. Psychol. 10 (2), 271 e301.

Macquet, A.-C., 2009. Recognition within the decision-making process: a case study of expert volleyball players. J. Appl. Sport Psychol. 21, 64e79. http://dx.doi.org/ 10.1080/10413200802575759.

Macquet, A.-C., 2010. Time management in the context of elite sport training. Sport Psychol. 24, 194e210.

Macquet, A.-C., 2013. Getting them on the same page: a method to study the consistency of HCs' and athletes' situation understanding during training ses sions and competitions. Sport Psychol. 27, 292e295.

Macquet, A.-C., Fleurance, P., 2007. Naturalistic decision-making in expert badminton players. Ergonomics 50, 1433e1450. http://dx.doi.org/10.1080/ 0014013070193452

Macquet, A.-C., Eccles, D.W., Barraux, E., 2012. What makes an orienteer an expert? A case study of a highly elite orienteer's concerns in the course of competition. J. Sport Sci. 30, 91e99. http://dx.doi.org/10.1080/02640414.2011.617774.

Macquet, A.-C., Kragba, K., 2015. What makes basketball players continue with the planned play or change it? A case study of the relationships between sensemaking and decision-making. Cognit. Technol. Work. http://dx.doi.org/ 10.1007/s10111-015-0332-4 (available on line).

Macquet, A.-C., Stanton, N.A., 2014. Do the coach and athlete have the same picture of the situation? Distributed situation awareness in an elite sport context. Appl. Ergon. 45, 724e733. http://dx.doi.org/10.1016/J.APERGO.2013.09.014.

McArdle, S., Martin, D., Lennon, A., 2010. Exploring debriefing in sports: a qualitative perspective. J. Appl. Sport Psychol. 22, 320e332. http://dx.doi.org/ 10.1080/10413200.2010.4811566.
Milne, C., Shaw, M., Steinweg, J., 1999. Medical issues relating to the Sydney Olympic Games. Sports Med. 28 (4), 287e298. http://dx.doi.org/10.2165/00007256 199928040-00006.

Mitchells, J., 1983. When disaster strikes: the critical incident stress debriefing process. J. Emerg. Med. Serv. 8, 36e39.

Omodei, M.M., McLennan, J., Whitford, P., 1998. Using a head-mounted video camera and two stage-replay to enhance orienteering performance. Int. J. Sport Psychol. 29, 115e131.

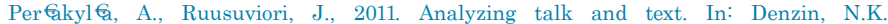
Lincoln, Y.S. (Eds.), The Sage Handbook of Qualitative Research. Sage, Thousand Oaks, CA, pp. $529 \mathrm{e} 543$.

Rees, T., Freeman, P., Bell, S., Bunney, R., 2012. Three generalizability studies of the components of perceived HC support. J. Sport Exerc. Psychol. 34 (2), $238 \mathrm{e} 251$.

Rowold, J., 2006. Transformational and transactional leadership in martial arts. J. Appl. Sport Psychol. 18, 312e325. http://dx.doi.org/10.1080/ 10413200600944082

Simon, H.A., 1996. The Sciences of Artificial. MIT Press, Cambridge, MA.

Stanton, N.A., Stewart, R., Harris, D., Houghton, R.J., Baber, C., McMaster, R. Salmon, P., Hoyle, G., Walker, G., Young, M.S., Linsell, M., Dymott, R., Green, D., 2006. Distributed situation awareness in dynamic systems: theoretical development and application of an ergonomics methodology. Ergonomics 49, 1288e1311. http://dx.doi.org/10.1080/00140130600612762.

Stanton, N.A., Salmon, P.M., Walker, G.H., Jenkins, D.P., 2010. Is situation awarenes all in the mind? Theor. Issues Ergonom. Sci. 11, 29e40. http://dx.doi.org/ 10.1080/14639220903009938.

Stanton, N.A., Salmon, P.M., Walker, G.H. , 2015. Let the reader decide: A paradigm shift for situation awareness in socio-technical systems. J. Cogn. Eng. Decision Mak 9 (1), 44e50. http://dx.doi.org/10.1177/155343414552297.

Stenling, A., Tafvelin, S., 2014. Transformational leadership and well-being in sports the mediating role of need satisfaction. J. Appl. Sport Psychol. 26, $182 \mathrm{e} 196$. http://dx.doi.org/10.1080/10413200.2013.819392.

Vidic, Z., Burton, D., 2011. Developing effective leaders: motivational correlates of leadership styles. J. Appl. Sport Psychol. 23, 277e291. http://dx.doi.org/10.1080/ 10413200.2010 .546827$.

Von Someren, M.W., Barnard, Y.F., Sandleberg, J.A.C., 1994. The Think Aloud Method: a Practical Guide to Modeling Cognitive Processes. Academic Press, London. 